\title{
How To Transfer Tacit Knowledge for Living Lab Practice - Consideration on Tacit Knowledge Representations
}

\author{
Mika Yasuoka \\ Roskilde University \\ mikaj@ruc.dk
}

\begin{abstract}
Despite strong attention and wide ranges of practice, living labs have hardly scaled up for a decade as expected. For living labs as one of the innovative methods for social challenges in cities with high complexity and uncertainty, one of the critical challenges is in knowledge transfer of its practice. Practical tacit knowledge for living lab is often embedded within process, organization and operation, and hardly externalized. The inexperienced practitioners face a lot of uncertainty in implementation of living lab without clues where to tackle. Aiming at promoting the living lab practice widely, this paper investigates tacit knowledge externalization with three different representations. The analysis and comparison of external representations indicate a strong compatibility pattern between representation styles and practitioners' maturity level on the relevant field. In the living lab practice, how to convey tacti knowledge should be considered carefully, depending on practitioners' maturity level.
\end{abstract}

\section{Introduction}

Living lab have been attracting global attentions as one of the innovative methods for social challenges with high complexity and uncertainty [1], [2]. In 2006, European Commission supports living labs as one of the common European innovation systems, and the European Network of Living Labs (ENoLL) was established. This EU Living Lab framework provided an impact in promotion of living lab in EU countries, and vast number of related projects were initiated and conducted, and success stories were reported widely [3], [4]. Since the launch of the initiative, wider interests were expressed also outside EU borders [5]. However, majority of practitioners and projects were still in EU and living lab practices outside Europe seems rather slow and a sign of scaling up is hardly seen. It is hard to say that knowledge about living lab practice as an innovation method is transferred, yet.
As factors that hinders scaling up, a lack of general consensus in a framework, a process and a definition has been pointed out [2], [6]. The lack of definition, for example, makes practitioners and decision makers feel living lab as an incomprehensible method in the immature stage. Towards this challenge, last couple of years, a structural and systematic analysis of the living labs literature have increased and discussed widely to consolidate its definition, process and framework [2], [7], aiming at supporting descriptive knowledge acquisition [8].

Supposing that the consensus was made, there is still another challenge to implement the living lab method in practice when there is no experienced practitioner in a project. Despite the fact that living labs have been around for nearly a decade, in terms of practical field knowledge, the current living lab researches have not provided a proper knowledge guidance to practitioners.

For example, to conduct a living lab, it is important to utilize not only descriptive knowledge such as frameworks and processes but also a wide variety of tacit knowledge to support long term co-creation with varied stakeholders. They are for example such knowledge as how to design co-creation environment for living labs, how to involve which stakeholders when, how to conduct co-creation to reach results, and how to support stakeholders' motivation for sustainable commitments. Such down to the earth knowledge about how things are practically done is called "procedural knowledge", also known as imperative knowledge or tacit knowledge [9], which is acquired through practice and exercised in the performance of some tasks. The tacit knowledge is hardly mentioned in the living lab reports because it is often buried in experience and practice. For that reason, unexperienced individuals and organizations who intends to conduct a living lab for the first time face a lot of practical problems even if they have prepared by acknowledging with many frameworks and cases.

Experienced practitioners have accumulated empirical knowledge to achieve successful living labs. Through the process of internalization, the knowledge 
become common sense to them, and disappear behind the scene. Therefore, the tacit knowledge of living labs has never consciously been externalized, or hardly targeted for research. The living lab method has wider applicability, flexibility and interpretability as the emerging method, which make it harder for practitioners to externalize the knowledge. However, in order to support Living Lab practice, it is an urgent matter to elicit consciously and share tacit knowledge for living lab practice through externalization process with wider practitioners.

In this article, we call a collection of knowledge for long-term co-creation acquired through experiencing living lab as "tacit knowledge for living lab practice". In order to externalize and share the tacit knowledge with wider living lab practitioners, and to contribute to scale up current living lab practice, we exercise external representations of tacit knowledge for living lab practice. More precisely speaking, through conscious process, we fist extract, then formalize, and finally visualize in knowledge presentation formats for conveying the living lab practical essence easier and wider.

This paper is organized as follows. First, some related research concerning about living labs and knowledge presentation are introduced. Among the various knowledge presentations, this article deals with three knowledge externalization methods: multimedia, pattern language, and a question-based representation. In Section 3, our approach to collect and externalize practitioners' tacit knowledge for living lab practice is explained, and evaluation, analysis and discussion about our external representations are conducted from "tacit knowledge for living lab practice" perspective. Finally, in Section 7, the conclusion is drawn.

\section{Related Research}

This section describes related works of this research. First of all, an overview of the current living lab research, and then several ways to codify potentially reusable tacit knowledge of the experienced living lab practitioners and these characteristics are reviewed. As knowledge externalization approaches, this article focuses on a use of multimedia, pattern language, and a question-based method.

\subsection{Living lab characteristics as an innovation method}

Living labs as a design innovation method involves stakeholders in their living contexts, with a long-term perspective, and seeks solutions through co-creation for the complexed societal problems (for example.
[10], [11]). Since no single professional has coherent or comprehensive knowledge to solve [1], co-creation is of critical importance. And since our modern society is highly complex and a full of uncertainty, stakeholders' living context becomes an important field of experiments, where iterative trials and developments are conducted.

The term, living lab, began to be used around 1998 [12], and living labs gradually started to attract attentions widely and many projects were conducted in Europe. Because of its wide applicability and interpretability, living labs were accepted and applied in varied domains. Leminen [13] analyzed the benefits of deploying living labs in three applied fields, innovation, living context and business chance, while Førlstad [12] investigated another fields such as R\&D, living context and research context. Living labs nowadays have a wide range of applied fields, and various definitions as well.

The definition of living lab is not settled, yet. ENoLL defines living labs as "user-centered, open innovation ecosystems based on systematic user cocreation approach, integrating research and innovation processes in real life communities and settings". Living lab practitioner and researcher, Bergvall-Kåreborn [14] defines living lab as "a user-centric innovation milieu built on every-day practice and research, with and approach that facilities user influence in open and distributed innovation processes engaging all relevant partners in real-life contexts, aiming to create sustainable values".

Although it has been criticized that the mainstream of current Living lab research has been practice-based, researchers on theoretical frameworks and analysis have been developed. Schuurman et.al. [2] analyzed scientific papers collected from databases of Google Scholar and Web of Science, and argued the need of a solid foundation of the field based on a concrete theoretical framework such as innovation theory. Dell'Ella [7], similarly, argued the importance of clarification of living lab methods and conciseness on its definition to position living lab in a scientific context. The increased number of papers reviewing the literature and cases have pointed out important common features. As also shown in the above living lab definitions, currently practitioners and researchers agreed, to some extent, that Living lab has characteristics such as co-creation, real-life settings, awareness of user [7], and technological implementation [15]. Although an ultimate definition of living lab has not been made yet [2], it has been widely agreed that a theoretical framework is important for the advancement of the field. Last couple of years, the core of living lab method has gradually condensed. 
However, living lab as practice-based approach, there are still many challenges to conduct living labs as its core tacit knowledge is not easily externalized in theories, definitions, and processes. Case descriptions have been strongly influenced with regional sociocultural characteristics, which is difficult to synthesize as meta-knowledge, or depict its tacit knowledge as external representation to other practitioners. Consequently, living lab method is hardly scaling up beyond local practice.

\subsection{Knowledge Representation}

Many externalization methods have been applied for knowledge transfer. Boose [8] showed cognitive maps, decision tables, rules, scripts, etc. as a method of presenting expertise, and as knowledge types, explained causal knowledge, terminology, constraints, example cases, procedures relations, facts, uncertain ties, etc. Among all, the most used method for knowledge representation is probably the declarative method, which is the method of transmitting the rules of thumb by being embedded in documents, expert dictionaries, manuals, demonstrations, simulations, decision support system, etc. Unlike programming or crafts, which is externalized and visualized as tangible knowledge outputs, highly abstract knowledge such as living lab practice including co-creation, process management, and team building, are difficult to externalize. It is obvious that the choice of knowledge representation of such abstract knowledge is a key component of knowledge transfer.

Among various externalization methods, three particular methods have been selected to externalize knowledge with a high affinity for abstraction. They are multimedia, pattern language and a question-based representation. Three methods are chosen as the authors have in-depth experiences in multimedia and pattern languages in different contexts, and the question-based method is recommended by experts.

2.2.1. Multimedia. With the progress of engineering and information technology, the use of multimedia is experimented as ways of declaration. Multimedia as a declarative method, can hold not only written text, but also captured images and videos that activate the human five senses such as sight, tactile and hearing. Multimedia representation is particularly effective in externalizing tacit embodied knowledge which typically craftsmen and athletes obtain in a course of experience accumulation. For craft technique externalization [9], researchers have demonstrated transferability of the tacit technique by digital means [16]-[19], For example, Wood and her colleagues [17] recorded and transmitted the skilled knowledge of wood carpenters using multimedia, based on the concept of bridges. Aytekin [19] investigated a digital platform as means of facilitating knowledge transfer of Turkish local crafts. For capturing and passing on distributed tacit knowledge of experts, Yasuoka [20] utilized a combined forms of multimedia, consisting of documents, pictures, movies and situ-practice. Crafts techniques and tacit knowledge behind the techniques were classified into concepts, element and keywords, then condensed and externalized with the four media types [20]. Knowledge management of craft technique with multimedia format has a huge potential to support endangered craft skills and knowledge.

2.2.2. Pattern language. Pattern language is a kind of declarative method and is used as intermediary between original to potential knowledge users. Pattern language is a description of common patterns embedded in good design and practice in a specific domain. Pattern language was originally proposed by Christopher Alexander [21] as a tacit knowledge externalization technique to support non-specialists in architectural and urban design domain [22], [23]. Pattern language by Alexander contains many common patterns that good design in architecture and urban development should have. Each pattern is described by an element such as a pattern ID, name, photographs or illustration showing the core messages. The details of the pattern are described together with use contexts and solutions, showing "In which context, which method should be taken". Pattern language advocated in the field of architecture and urban design has been widely deployed and utilized in various engineering and information system fields such as software development [24], scrum process [25], interaction design [26]. Although similar knowledge can be described simply in texts, the recipient of pattern language benefits from the enriched descriptive representation combined with various forms and visuals that helps approximating the relationship of receivers' existing knowledge.

2.2.3. Questions. The power of questions to transfer knowledge has been recognized and practiced since the days of Socrates and Confucius. Questions have typically been used to represent and transfer knowledge in the context of learning, but a scope of application can be easily expanded also in the complexed conceptual and abstract knowledge field. Cooper [27] considered questions as "unusual representation in knowledge resources", and discussed the reuse of knowledge, by exemplified with two system incorporating question-based representation. Cooper evaluated questions as a way to engage people 
without intimidating, and to support practitioners' reflection. Hmelo-Silver and Barrows [28] pointed out the value of questioning based dialogues in collaborative knowledge acquisition such as interpretation and synthesis. Anzai and Shiose [29] also discusses question-based dialogues as a tool for facilitating knowledge sharing in inclusive design workshops. Together with dialogues, questions can provide richer pragmatic constraints on knowledge transfer than either component can achieve alone [30]. This question-based representation in this case should be considered separately from the general and routine questions that are often found in the FAQs. The questions discussed here are for knowledge transfer in a form of representation that brings reflection in action [27], [31], identifies the nature of the problems, disrupts stereotypes and turn the objective problems to subjective challenge [29].

\section{Research design}

Aiming at transferring tacit knowledge for living lab practice to wider practitioners, the authors conducted a series of experiments, in which practitioners' experiences were collectively extracted and externalized [32], [33](Step 1). The process was conducted through two workshops for collecting tacit knowledge for living lab practice, and an analysis session. In analysis session, collected items were analyzed and categorized. The depicted knowledge was finally externalized in a form of three different representations and evaluated (Step 2). The Step 1, the knowledge extraction process in workshops and analysis were reported previously in a conference [32], [33], so that in this article, only the basic frame and result will be presented.

\subsection{Step 1: Workshops and knowledge extraction}

In order to collect empirical knowledge of living lab from experienced practitioners, the authors conducted a data collection workshop, which were called the Wisdom of Practice workshops. Two workshops were held in Copenhagen, Denmark and Tokyo, Japan in 2018, and total 51 people from Europe, North America and Asia with different nationalities, professions and domains participated. The workshops consisted of ten presentations and group discussions. The presentations were made by selected ten practitioners and researchers for sharing personal experience and thoughts on the success or failure of living lab projects, which were mainly used to trigger participants' reflections. After the presentations, participants in the workshops were divided into small groups with 4-6 members and analyzed the key knowledge of success and failure experience together for 1.5 hours. In order to encourage discussions and reflections, and support the externalization of tacit knowledge for living lab practice, the authors prepared a few templates which were distributed to the groups. Participants extracted key message and know-how from the presentations and discussions by utilizing the templates while sharing the reflections of the presentations and their personal experiences in other projects. In the end of the two workshops, a total 526 pieces of externalized tacit knowledge for living lab practice were collected.

\begin{tabular}{|c|l|}
\hline No & \multicolumn{1}{|c|}{ Key words } \\
\hline \multicolumn{2}{|c|}{ Category 1: Co-creation } \\
\hline 1 & Start with questions \\
\hline 2 & Stop hypnotize \\
\hline 3 & Share personal stories \\
\hline 4 & Redefine "us" \\
\hline 5 & Externalize \& get feedbacks \\
\hline 7 & Create stranger's perspective \\
\hline 8 & Search what can be changed \\
\hline 9 & Try fonly democracy $\&$ fail fast \\
\hline 10 & Start with hard-core MVP \\
\hline \multicolumn{2}{|c|}{ Section 2: Process management } \\
\hline 11 & Visualize for discussion \\
\hline 12 & Participation affordance \\
\hline 13 & Our place, our space \\
\hline 14 & Special guest \\
\hline 15 & Not satisfied with workshop \\
\hline 16 & Accumulate small successes \\
\hline 17 & Timely feedback to participants \\
\hline 18 & Time for reflection \\
\hline 19 & Multi-speed \\
\hline 20 & Be-flexible \\
\hline 21 & Weakness disclosure \\
\hline \multicolumn{2}{|c|}{ Section 3: Team building } \\
\hline 22 & Gather multi specialties \\
\hline 23 & Limit core stakeholders \\
\hline 24 & Capture charisma \\
\hline 25 & Community collaboration \\
\hline 26 & Start with the passionate \\
\hline 27 & CSV: Creating shared "vision" \\
\hline 28 & Attractive objective \\
\hline 29 & Strategical wording and space \\
\hline 30 & Achieve trust from stakeholders \\
\hline & 1. The 30 knowedge for \\
\hline
\end{tabular}

Figure 1. The $\mathbf{3 0}$ knowledge for living lab

The primary 526 knowledge about living lab were analyzed, classified, categorized and integrated, by 
using the affinity diagram, the KJ method [34]. As a result of analysis, three categories and the 30 types of "tacit knowledge for living lab practice" were yielded. Three categories are Co-creation, Process management and Team building. The result is shown in the Figure 1.

The 30 tacit knowledge for living lab practice presented in Figure 1 were extracted and analyzed through a bottom-up two-stage process by practitioners and the authors. Through the two step process, the final collection of the 30 tacit knowledge for living lab practice achieved further could be interpreted as valid representations with various elements and considerations extracted by living lab practitioners.

\subsection{Step 2: Knowledge representations}

Next, the 30 tacit knowledge for living lab practice were externalized in three knowledge representation forms. The utilized externalization formats are multimedia, pattern language and questions.

3.2.1. Externalization with multimedia. All 30 tacit knowledge for living lab practice were externalized in multimedia format, using a mix of texts, photographs and videos. The texts explain when the knowledge can be used, what kind aspects of the knowledge can be considered as tacit knowledge, and what kind of results can be expected by using the knowledge. Photos and videos visually show how the particular tacit knowledge can be observed in different cases. As an example, let us explain with "09: Try fast \& fail fast (refer Figure 1)" which explains the importance of testing and verifying ideas as fast as possible and learning from failures. For 09, one document, nine pictures and two videos were prepared. As shown in Figure 2, photos show a few different examples from the real living lab cases.

3.2.2. Presentation of pattern language. All 30 tacit knowledge for living lab practice were externalized using patter language. Referring to the description of Alexander [21], the living lab pattern consists of five elements. They are (1) a pattern name, (2) an illustration, (3) summary, (4) detail (explaining context and expected results) and (5) related cases. Figure 3. is an example with tacit knowledge 09. A pattern name (1) is described a simple short sentence. Illustration (2) is abstract but concrete enough to describe conceptual tacit knowledge. Both name and illustration are carefully chosen so that users can motorize and recall pattern easily. Summary (3) describes with further details still with short and concise expression. In addition, further details (4) are described such as context, problem, barriers, solution, actions, and

possible consequence, which make the users imagine further with details. Finally, one or two related cases (5) are described in a short story format.
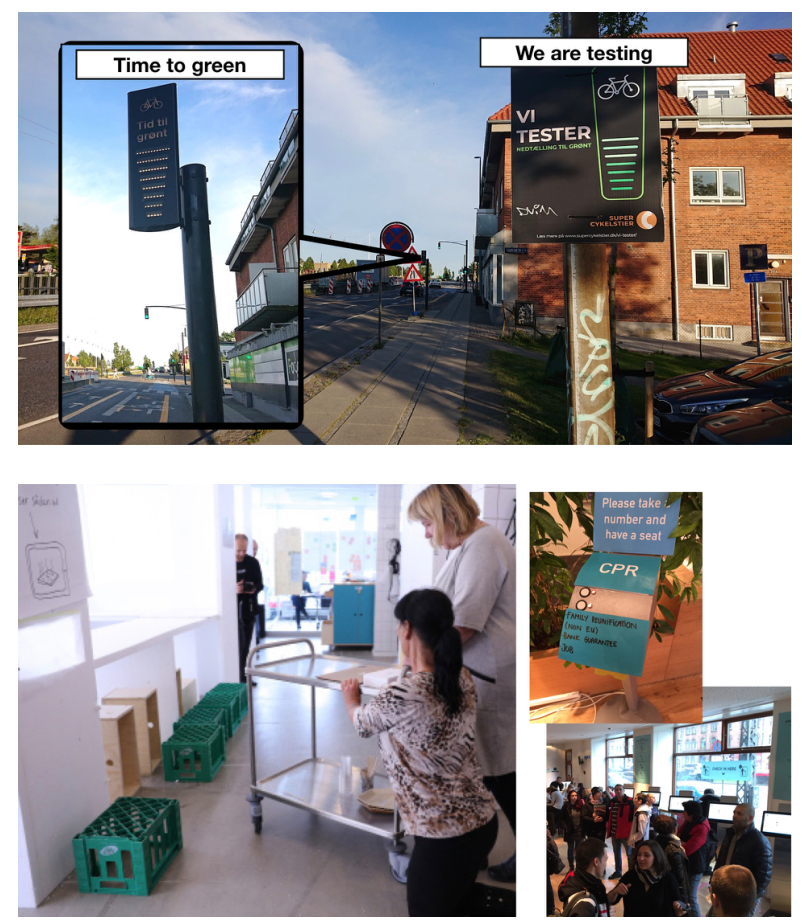

Figure 2. Examples of photo representations Top: the signals for bikes are under the test, Bottom: plastic and paper mock ups are tested

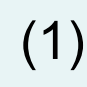

(1)

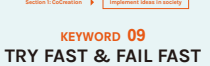

(2)

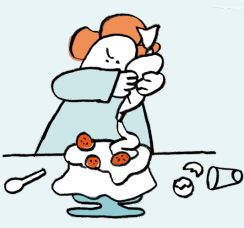

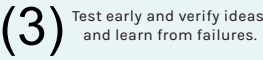

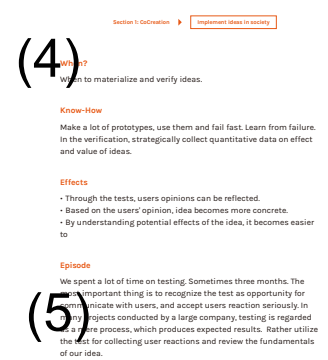

Figure 3. Examples of pattern language

3.2.3. The use of questions. All 30 tacit knowledge for living lab practice were externalized using a form of questions. Total 33 questions were created including questions related to the three categories. The questions are designed so that the three categories and the 30 tacit knowledge for living lab practice could be derived as an answer. The key in this question-based representation is in its composition. Each question consists of a $5 \mathrm{~W} 1 \mathrm{H}$ question, and three to five choices, 
an answer, and a dialogue instruction. The dialogue instruction is used to understand reasons behind the question and answers. Figure 4. is an example question with tacit knowledge 09.

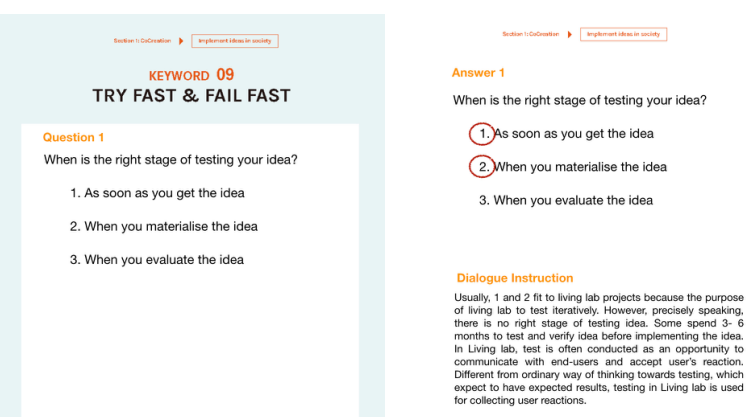

Figure 4. Examples of questions

\section{Evaluation}

Mixed method [35] was applied to evaluate three external representations of tacit knowledge for living lab practice. As evaluation, we conducted an interviewbased method with a 7 score scale, using an evaluation template. The evaluation sessions were conducted during 2020 January to April, approximately one hour for each, with six evaluators. Among six evaluators, two were experienced practitioner of living lab, another two were intermediate practitioners, who have some knowledge about living lab but no practical experience, and plans to conduct a living lab project. Finally, the other two were beginners who were interested in but never experienced or involved in living lab as practice. The interviews were conducted face to face or online due to the limited social condition.

The authors conducted interview with six evaluators who evaluated three external presentations based on a format the authors prepared. First, the evaluators browsed three types of external representations for 30 minutes. Next, the authors interviewed for 30 minutes, based on the pre-defined evaluation process and criteria shown in Table 2. The evaluators evaluated about 1) the 30 extracted tacit knowledge for living lab practice in general and 2) three external representations on a scale of 1 (Strongly disagree), 1 (Strongly disagree), 2 (Disagree), 3(More or less disagree), 4 (Neutral), 5 (More or less agree), 6 (Agree), and 7 (Strongly agree). The evaluators could also freely express their thoughts and opinions during the evaluation process.
Table 1. Characteristics of six evaluators

\begin{tabular}{|c|l|c|l|}
\hline ID & Expertise & Experience & \\
\hline E & Beginner & $\begin{array}{c}\text { Interested in Living lab } \\
\text { and have studied for 3 } \\
\text { months. }\end{array}$ & FtoF \\
\hline E & Beginner & $\begin{array}{c}\text { Has just started to know } \\
\text { the term Living labs and } \\
\text { got interested in }\end{array}$ & Online \\
\hline E & Intermediate & $\begin{array}{c}\text { Researched on living labs } \\
\text { for 7 years and planed } \\
\text { several living labs but } \\
\text { never practice before. }\end{array}$ & FtoF \\
\hline E & Intermediate & $\begin{array}{c}\text { Plan to run a living lab } \\
\text { project in a few months. }\end{array}$ & Online \\
\hline E & Experienced & $\begin{array}{c}\text { Conducted 7 living labs } \\
\text { on social technology } \\
\text { projects }\end{array}$ & FtoF \\
\hline 5 & & $\begin{array}{c}\text { Conducted three living } \\
\text { labs for last 5 years as } \\
\text { regional development } \\
\text { projects. }\end{array}$ & Online \\
\hline 6 & Experienced & r \\
\hline
\end{tabular}

Table 2. 6 Questions and evaluation criteria

\begin{tabular}{|c|c|c|}
\hline Q & Criteria & Scale \\
1 & $\begin{array}{c}\text { Generally speaking, the described 30 } \\
\text { knowledge is reflected important tacit } \\
\text { knowledge of experienced practitioners. }\end{array}$ & $1-7$ \\
\hline 2 & $\begin{array}{c}\text { Each externalization describes tacit } \\
\text { knowledge of experienced practitioners? }\end{array}$ & $1-7$ \\
\hline 3 & $\begin{array}{c}\text { Did you learn anything from } \\
\text { externalization? }\end{array}$ & Y/N \\
\hline 4 & If so, what did you learn? & Open \\
\hline 5 & Will externalization trigger your next & Yction? \\
\hline 6 & If so, what is your next step? & Open \\
\hline
\end{tabular}

Table 3. Three discussed topics

\begin{tabular}{|c|c|c|}
\hline ID & Key word & Summary \\
\hline 09 & $\begin{array}{c}\text { Try Fast \& } \\
\text { Fail Fast }\end{array}$ & $\begin{array}{c}\text { It is important to test early and } \\
\text { verify ideas, and learn from } \\
\text { failures }\end{array}$ \\
\hline 11 & $\begin{array}{c}\text { Visualize } \\
\text { for } \\
\text { discussion }\end{array}$ & $\begin{array}{c}\text { It is important to visualize in } \\
\text { pictures and diagrams \& establish } \\
\text { common ground among } \\
\text { stakeholders. }\end{array}$ \\
\hline 19 & $\begin{array}{c}\text { Multi- } \\
\text { speed }\end{array}$ & $\begin{array}{c}\text { Be aware of different and interests } \\
\text { of participants. It is important to } \\
\text { adjust their involvement. }\end{array}$ \\
\hline
\end{tabular}

With regard to the three external representations, we chose three tacit knowledge as discussion items among 30 as it was practically difficult to get comments on all 30 items. The three selected items are 
shown in Table 3, which are ID-09:Try Fast \& Fail Fast, ID-11: Visualize for discussion, and ID-19:Multispeed. Each evaluator evaluated the three items with the three external representations (multimedia externalizations, patter languages and questions), and provided scores and comments about their evaluations.

\section{Results}

\subsection{Tacit knowledge representation}

The overall evaluation on the 30 sets of externalized knowledge was generally well as shown in the second left "General" column in Table 4. Many evaluators commented together with positive evaluations; "I think I got a better perspective (E1)", "I felt strong empathy that many other practitioners faced similar challenges that I am in trouble now. I got a lot of concrete advice by reviewing the 30 sets (E3) ", "I wasn't aware before browsing, but there were many useful externalized knowledge, which I recognize as my hidden mindset (E5)", "While browsing the 30 sets, I recalled my experience again and felt empowered that my experience was valuable (E6)" On the other hand, there were some negative comments or critics as well. One of the beginners (E2) mentioned that "I think good information is collected. However, I wish they showed more concrete examples in each externalization. I probably have too little experience, though."

Table 4. Evaluation results in the 7 scale

\begin{tabular}{|c|c|c|c|c|}
\hline & General & Multimedia & Pattern & Question \\
\hline E1 & 7 & 7 & 5 & 7 \\
\hline E2 & 7 & 6 & 5 & 7 \\
\hline E3 & 6 & 7 & 6 & 3 \\
\hline E4 & 7 & 6 & 6 & 7 \\
\hline E5 & 6 & 7 & 7 & 5 \\
\hline E6 & 7 & 5 & 7 & 5 \\
\hline
\end{tabular}

\subsection{Tacit knowledge externalization}

Next, let us look at evaluations of each external representation. E1 evaluated highly question and multimedia while she put lower score regarding the pattern language. E1 didn't provide any particular reasons except "It is easy to understand". Although the comment sounded rather positive, the evaluation score was rather low. Concerning about multimedia, E1 mentioned that the ID-09 knowledge is difficult to understand only with document, but photos and videos helped a lot in understanding. He mentioned, "when combining the document with the photos and videos, the understanding of the document was increased." E1 also commented that ID-19 was difficult to understand even with photographs and videos. Interestingly, E1 mentioned that "it was easier to understand ID-19 with the document."

E2 evaluated highly in the order of question and multimedia. E2 thought answering the questions made her to consider a right aspect to a problem. Regarding the externalization utilizing multimedia, she mentioned that "photos and videos with strong impacts can deepen understandings than the documents". Particularly "it was a good opportunity to see knowledge from different angles". Because she could imagine in her head easily even when the message behind the representation was initially incomprehensible. However, this doesn't apply to all 30 knowledge, some of which was hard to understand even with varied external representations offered by multimedia. Similar to E1, E2 also mentioned Pattern language as "hard to understand".

$\mathrm{E} 3$, the intermediate practitioner, evaluated highest with the Multimedia representation and the evaluation on pattern language was also high. E3 commented that "I feel that I could narrow down what I have to pay particular attentions just by browsing the 30 sets of externalization as I could see a way of thinking of the experienced practitioners.

E4 scored the most in question while evaluations on multimedia and pattern were also high at the score 6 . She particularly interested in combining different external representations for example questions and pattern. For example, she suggested to provide a few questions after each section so that she could review her understanding after browsing the pattern.

E5 put a low rating on questions because "the process of answering the questions one by one is tedious", and "It lacks overview." It was also pointed out that the information provided in the question-based representation was quite limited, so that the experienced practitioners could not help considering beyond the description. To think "there must be more to say than the short selections of answers." was rather stressful.

E6 evaluated highly with pattern language with strong enthusiasm. He mentioned that the short description of the pattern language had decent granularity so that he could freely expand his thought to his own wider experience and reflected upon it. From time to time, he also recalled some key aspects to pay attention, which played a valuable reminder of things he had forgotten but important.

\subsection{Trigger to action}

The last two question in the interview to the six evaluators was whether they learn from external representations and whether the learning would lead to 
action. All evaluators commented "yes" to the questions. This is probably because the evaluators were originally interested in living lab and have actively been seeking for good advice for their practice. However, depending on evaluators, there was a big difference in which external representation was most influential to them. E2 strongly supported the form of question. By checking the questions, browsing the list of answers, he started to think about something he had never thought about before. The reflection by browsing the answer choices, answering question, having interactive dialogues gave him various ideas for practice. On the contrary, E5 and E6 evaluated pattern language highest because "pattern language was explicitly shown what I did not think clearly as a key for the living lab practice, but I totally agreed its importance (E5)", and "Pattern language conveyed right amount of information with right granularity (E6)."

Both E5 and E6 mentioned ID-19 as something they would consider next time they were in their fields. Similarly, E2 mentioned about ID-09, as something they want to try out when they involved in a living lab project.

\section{Discussion and reflection}

In this article, based on the extracted tacit knowledge, the three external representations, multimedia, pattern language and questions, were tested and evaluated. The evaluation suggested that the three external representations have their own unique characteristics, and there is no best method for everyone under any conditions. In this section, we are going to discuss some findings through externalization and evaluation, and discuss future issues.

\subsection{Characteristics of the representations}

In the evaluation sessions, the evaluators commented different aspects of the three tacit knowledge external representations. Representations using the question formats were most popular among two beginners. Although experienced practitioners criticized that questions could not provide a comprehensive perspective, two evaluators who had no experience in living lab were clearly fond of the style. It can be interpreted that the beginners often do not know what to pay attention in conducting a living lab, and questions and answers could narrow down the scope of consideration. In other words, the beginners can be overwhelmed easily with rich information as they do not to know how to. For beginners, it is a challenging task to grasp or comprehend a whole view, so probably there is no urgent need of overview. As indicated in a comment E1 about pattern language, "Rather than the manuals like pattern language or methods, I would like to understand living lab concept". The questions provide, in a sense, a right amount of information and they are guaranteed all the necessary information are presented in front of them. The question-based representations created an easy context for what is generally considered important.

Representation using multimedia was also highly evaluated by almost all evaluators. Many of the comments from E1 and E2, namely beginners, showed visual representations such as photos and videos appealed them, which can be interpreted that the emphasis on visual expression is suitable for beginners. The documents are also useful for embodying knowledge, while visual expressions can transmit information necessary for each subject with a decent granularity than texts and keywords. Multimedia became more effective also due to its combination of multiple representations prepared in one platform.

Pattern language was most highly evaluated by the experienced practitioners. They expressed their opinions vigorously, and talked about their related experiences energetically. The comments indicate that the value of pattern language was in its ability to initiate appropriate reflections on the practitioner's own experiences, which has high proximity with the exemplified knowledge. Furthermore, the knowledge that the practitioners have been recognized but not externalized by themselves, are expressed verbally or visually in a form of pattern language. By browsing the patterns, it seems that the practitioners' experience was amplified and empowered. The practitioners expressed their view more freely on a particular knowledge as if they were the one who described. However, not everyone has the same view. Although the beginners found pattern language was also interesting, they were hardly impressed by, and sometimes confused to depict essence from.

\subsection{External representations and maturity}

It is a well-known learning behavior that acquiring new knowledge often lead some action [36]. The fact that all evaluators answered that they could imagine their next step, indicates that the 30 tacit knowledge for living lab practice have been appropriately described and extracted some essence for the knowledge about living labs. Interestingly, all evaluators performed their reflection in action [31] at their own level, in spite that they favored different externalization and expressed differently. The triggered representations varied greatly depending on the person. Some found that the question could help them to identify the next important action, 
while others found pattern language most important as they recognized the value of their practice and decided to conduct the action more consciously.

The analysis and evaluation of three external representations of tacit knowledge for living lab practice, showed that the question-based representation was suitable to convey knowledge as learning experience, while pattern language tends to be accepted by the experienced practitioners. Since the evaluation was conducted just by interviews with six practitioners, it is not durable to make a general evaluation. However, our results indicate that there is a certain correlation between experience levels on living lab and externalization characteristics. In other words, a way to convey knowledge may be related to knowledge receivers' maturity level. In practice fields where gather practitioners with various maturity levels, externalization approach should be well considered depending on who want to utilize, what kind of knowledge to utilize and how to utilize knowledge.

\section{Conclusion}

In this article, in order to promote living lab practice, the tacit knowledge extraction for living lab practice, and three types of external representations are examined. In living lab practice, there are a lot of tacit knowledge about how to design, organize and operate living labs, which are not externalized. The evaluation of tacit knowledge externalization itself were highly accepted, while the evaluation of the three types of external representations varied greatly depending on the evaluators. Our analysis suggests that the maturity level of the practitioners who utilize the described knowledge in the living lab practice and the format of the external representation are highly correlated. The tacit knowledge of living lab practice is difficult to convey if it is only in writing or document. In the field of knowledge transfer such as living lab practice, it is still a major issue to consider how to externalize knowledge in an appropriate manner, and transmit the knowledge to practitioners. In the field where there are practitioners with many maturity levels, the format of external representation should be carefully considered.

With no doubt, this paper exposed some challenges. The proposed various knowledge externalization methods were in a sense, arbitrarily selected as methods considered appropriate for abstract knowledge. It would be valuable to deploy different externalization approaches to understand relations between external representation formats and ability of knowledge transfer. In addition, the limited number of evaluators and the limitation caused by online interviews due to social conditions certainly influenced the analysis. It is possible to improve the evaluation and analysis quality through refining better framework with more appropriate evaluation protocol.

Along with the development of digital and communication technology, human knowledge became possible to externalize in various ways. Some externalization approach, which were considered impossible to record and transfer became possible. Nowadays knowledge externalization utilizes not only visual, but also other five senses such as tactile, smell and hearing. The target of knowledge externalization is not only abstract knowledge such as tacit procedural knowledge used for the implementation of living labs, but also skills accumulated by long-term technical training such as traditional crafts [20]. This indicates that the studies on tacit knowledge externalization open up new ways of knowledge transfer, and also created new possibilities in wider domains.

\section{References}

[1] G. Fischer, "Symmetry of ignorance, social creativity, and meta-design," Knowledge-Based Syst., 2000, doi: 10.1016/S0950-7051(00)00065-4.

[2] D. Schuurman, L. De Marez, and P. Ballon, "Living Labs: a systematic literature review," Open Living Lab Days 2015, 2015.

[3] B. Dutilleul, F. A. J. Birrer, and W. Mensink, "Unpacking European Living Labs: Analysing Innovation's Social Dimensions," Cent. Eur. J. Public Policy, 2010.

[4] EC ENoLL, "European Network of Living Labs (ENoLL)," Openlivinglabs.eu, 2015. http://www.openlivinglabs.eu/.

[5] M. Yasuoka, F. Akasaka, A. Kimura, and M. Ihara, "Living labs as a methodology for service design - An analysis based on cases and discussions from a systems approach viewpoint," Proceedings of International Design Conference, DESIGN, vol. 1, no. 2012. pp. 127136, 2018, doi: 10.21278/idc.2018.0350.

[6] D. Schuurman, A.-L. Herregodts, A. Georges, and O. Rits, "Innovation Management in Living Lab Projects: The Innovatrix Framework," Technol. Innov. Manag. Rev., 2019, doi: 10.22215/timreview/1225.

[7] C. Dell'Era and P. Landoni, "Living lab: A methodology between user-centred design and participatory design," Creat. Innov. Manag., 2014, doi: 10.1111/caim.12061.

[8] J. H. Boose, "A survey of knowledge acquisition techniques and tools," Knowl. Acquis., 1989, doi: 10.1016/S1042-8143(89)80003-2.

[9] I. Nonaka and H. Takeuchi, The Knowledge-creating Company. Oxford University Press, 1995.

[10] M. Hossain, S. Leminen, and M. Westerlund, "A systematic review of living lab literature," Journal of Cleaner Production. 2019, doi: 10.1016/j.jclepro.2018.12.257.

[11] B. B. Kareborn and A. Stahlbrost, "Living Lab: an open 
and citizen-centric approach for innovation," Int. J. Innov. Reg. Dev., vol. 1, no. 4, p. 356, 2009, doi: 10.1504/IJIRD.2009.022727.

[12] A. Følstad, "Living Labs for innovation and development of information and communication technology: a literature review," Electron. J. Virtual Organ. Networks, vol. 10, no. August, pp. 99-131, 2008.

[13] S. Leminen and M. Westerlund, "Towards innovation in Living Labs networks," Int. J. Prod. Dev., vol. 17, no. 1/2, p. 43, 2012, doi: 10.1504/IJPD.2012.051161.

[14] B. Bergvall-Kåreborn, M. Holst, and A. Ståhlbröst, "Concept design with a living lab approach," in Proceedings of the 42nd Annual Hawaii International Conference on System Sciences, HICSS, 2009, doi: 10.1109/HICSS.2009.123.

[15] A. G. Nystrom and S. Leminen, "Living lab. A new form of business network," Concurrent Enterprising (ICE), 2011 17th International Conference on. pp. 1-10, 2011.

[16] N. Wood, "Transmitting craft knowledge: designing interactive media to support tacit skills learning," 2006.

[17] U. H. Lassen and N. Wood, "Plumb line scribe': using multimedia to preserve traditional craft skills," Cr. Res. $J$., vol. 4, no. 1, pp. 31-52, 2013.

[18] N. Wood, "Silent witness , using video to record and transmit tacit knowledge in creative practices," in Hantverkare emellan / Between craftspersons, G. Almevik, Ed. Craft Laboratory, Mariestad, University of Gothenburg, 2014, pp. 56-69.

[19] B. A. Aytekin and K. Rizvanoğlu, "Creating learning bridges through participatory design and technology to achieve sustainability in local crafts: a participatory model to enable the transfer of tacit knowledge and experience between the traditional craftsmanship and academic education In," Technol. Des. Educ., vol. 29, no. 3, pp. 603-632, 2019.

[20] M. Yasuoka, "Designing Knowledge Management System for Supporting Craftsmen's Collaboration beyond Temporal Boundaries," Proc. 53rd Hawaii Int. Conf. Syst. Sci., vol. 3, pp. 4880-4889, 2020, doi: 10.24251/hicss.2020.599.

[21] C. Alexander, "The Timeless Way of Building," New York Oxford University Press. 1979, doi: 10.1080/00918360802623131.

[22] A. Dearden, J. Finlay, L. Allgar, T. Grange, B. Park, and B. Mcmanus, "Using Pattern languages in Participatory Design," in Participatory Design Conference, 2002, pp. 104-113.

[23] A. Dearden, J. Finlay, L. Allgar, and B. McManus,
"Evaluating pattern languages in participatory design," in Conference on Human Factors in Computing Systems - Proceedings, 2002, doi: 10.1145/506486.506535.

[24] P. Avgeriou and U. Zdun, "Architectural patterns revisited: A pattern language," in 10th European Conference on Pattern Languages of Programs, EuroPLoP 2005 - Preliminary Conference Proceedings, 2005.

[25] M. Beedle, M. Devos, Y. Sharon, K. Schwaber, and J. Sutherland, "SCRUM: An extension pattern language for hyperproductive software development," Pattern Lang. Progr. Des., 1999, doi: 10.1.1.15.3987.

[26] J. O. Horchers, "A pattern approach to interaction design," AI Soc., 2001, doi: 10.1007/bf01206115.

[27] L. P. Cooper, "The power of a question: A case study of two knowledge capture systems," Proc. 36th Annu. Hawaii Int. Conf. Syst. Sci. HICSS 2003, 2003, doi: 10.1109/HICSS.2003.1174258.

[28] C. E. Hmelo-Silver and H. S. Barrows, "Facilitating collaborative knowledge building," Cogn. Instr., 2008, doi: 10.1080/07370000701798495.

[29] T. Shiose, "Inclusive Design," in Field Informatics, Springer, Berlin, Heidelberg, 2012, pp. 107-121.

[30] N. Asher and A. Lascarides, "Questions in Dialogue.," Linguist. Philos., vol. 21, pp. 237-309, 1998, doi: https://doi.org/10.1023/A:1005364332007.

[31] A. D. Schön, The Reflective Practioner: How Professionals Think In Action. New York, USA: Ingram Publisher Services, 1983.

[32] F. Akasaka, A. Kimura, M. Ihara, and M. Yasuoka, "How to make successful Living Labs? : Extraction and description of key know-how for Living Lab projects," in International Conference on Serviceology (ICServ), 2018.

[33] F. Akasaka, M. Yasuoka, M. Nakatani, A. Kimura, and M. Ihara, "Patterns for living lab practice: describing key know-how to promote service co-creation with users," Int. J. Autom. Technol., vol. 14, no. 5, pp. 769778, 2020, doi: 10.20965/ijat.2020.p0769.

[34] R. Scupin, "The KJ method: A technique for analyzing data derived from Japanese ethnology," Hum. Organ., 1997, doi: 10.17730/humo.56.2.x335923511444655.

[35] J. C. Greene, V. J. Caracelli, and W. F. Graham, "Toward a Conceptual Framework for Mixed-Method Evaluation Designs," Educ. Eval. Policy Anal., 1989, doi: 10.3102/01623737011003255.

[36] D. A. Kolb, "Experiential Learning: Experience as The Source of Learning and Development," Prentice Hall, Inc., 1984, doi: 10.1016/B978-0-7506-7223-8.50017-4. 